\title{
Knowledge and Attitude Regarding Cervical Cancer and Human Papillomavirus in Oman
}

\author{
"Marwa Al Raisi, ${ }^{1}$ Tagharid Al Yahyai, ${ }^{1}$ Rahma Al Kindi ${ }^{2}$
}

\begin{abstract}
Objectives: This study aimed to assess the knowledge of and attitude toward cervical cancer and human papillomavirus (HPV) among Omani women aged 18 years and older. Methods: This cross-sectional survey was conducted between September 2019 and February 2020 in primary healthcare facilities throughout Oman. A selfadministered questionnaire was distributed to assess women's knowledge and attitude regarding cervical cancer and HPV. Results: A total of 805 women participated in the study (response rate: 89\%). Two-thirds of the participants had heard about cervical cancer (67.5\%) while fewer were aware of HPV (15.8\%). Approximately one-third of the women identified HPV as a risk factor for developing cervical cancer (38.9\%). Very few participants knew of HPV vaccines (10.1\%). A major source of information regarding both cervical cancer and HPV was social media (33.0\%), as compared to healthcare providers (16.9\%). Despite the poor knowledge, almost half of the participants were open to having their daughters (47.0\%) and other schoolgirls (41.2\%) vaccinated. Conclusion: Most participants had poor knowledge of cervical cancer and HPV, even those with a personal or family history of cervical cancer. The main source of knowledge was social media. Most participants were open to the idea of offering the HPV vaccine to their daughters and middle school-aged girls. Incorporating information about cervical cancer and HPV into school curricula and improving access to trusted medical knowledge through social media may help in enriching the public's knowledge and, possibly, correcting misinformation and related myths.
\end{abstract}

Keywords: Papillomavirus Vaccines; Cervical Cancer; Surveys and Questionnaires; Risk Factors; CommunityInstitutional Relations; Knowledge; Attitude; Oman.

\section{Advances in KNOWLEDGE}

This study showed that most participants had poor knowledge of cervical cancer and human papillomavirus (HPV). Despite this, approximately half were accepting of the HPV vaccine. Therefore, healthcare providers and decision-makers should be vigilant and prepare a nationwide awareness programme to enrich the public's knowledge of cervical cancer, HPV and its implications.

To the best of the authors' knowledge, this is the first study conducted in all the governorates of Oman that assesses the knowledge of and attitude towards cervical cancer and HPV among Omani women.

\section{Applications to Patient Care}

The findings of this study provide useful information that could form the basis for educational campaigns and initiatives focusing on cervical cancer and the importance of HPV vaccination. This would result in increased utilisation of the screening programme, improved health outcomes and a significant reduction in the incidence of cervical cancer.

This survey demonstrates public acceptance of the vaccine; hence, policymakers must initiate urgent plans to integrate the vaccine into the national immunisation schedule.

$\mathrm{H}$ UMAN PAPILLOMAVIRUS (HPV) INFECTION has been identified as a precursor to cervical cancer. There are many HPV carcinogenic genotypes, but types 16 and 18 are the most commonly identified in cervical cancer. ${ }^{1,2}$ In a recent study from Oman, the prevalence of HPV was found to be $17.8 \%$, with 22 different types identified, some of which were found to be carcinogenic, thus posing a high risk. The highest prevalence was for the low-risk type 54 (12.3\%), followed by the high-risk type 82 (10.77\%). ${ }^{3}$

According to the Global Cancer Observatory (GLOBOCAN) estimates of 2020, the incidence of cervical cancer was 604,127 (3.1\%) worldwide, which ranks it as the seventh most common cancer overall and fourth most common in women. ${ }^{4}$ The corresponding worldwide mortality is 341,831 (7.7\%), which makes cervical cancer rank fourth in cancerrelated mortality in women of all ages. ${ }^{4}$ In Oman, cervical cancer is the fourth most common cancer in women of all ages and the third most common in women aged 15 to 44 years. ${ }^{5,6}$ Approximately 77 new cervical cancer cases are diagnosed annually in Oman, with a total of 41 deaths as per the $2019 \mathrm{HPV}$ Information Centre estimates. ${ }^{6}$

The HPV vaccine was introduced with different combinations of HPV genotypes. In many countries, the vaccine was approved as a preventative measure against cervical cancer. For the vaccine to provide adequate immunity, it should be administered years before exposure to the virus. This necessitates its use 
much before the individual becomes sexually active, preferably during prepubertal age. ${ }^{7}$ Many developed countries have integrated the HPV vaccine into their national immunisation programmes. ${ }^{8}$ Among the Middle East and North African region, only one country, the United Arab Emirates, offers the HPV vaccine as a part of their immunisation schedule. ${ }^{9}$ In Oman, the HPV vaccine is not yet included in the Expanded National Immunization Programme and is not systematically provided by the institutes of the Ministry of Health. ${ }^{10}$

The incidence of cervical cancer has dropped significantly after the introduction of cervical cancer screening. In the UK, the incidence rates have declined by $24 \%$, and in the USA, cervical cancer has moved from within the top 10 to the $14^{\text {th }}$ place since the introduction of screening. ${ }^{11-14}$ In a study conducted in Sweden, follow-up of more than one million females for more than 10 years showed a substantial reduction in the incidence of cervical cancer, especially among those vaccinated before the age of $17 .^{15}$

Based on a study conducted in 2019, the estimated worldwide incidence of cervical cancer is predicted to be 44.4 million by the year $2069 .{ }^{16}$ Unfortunately, twothirds of the new cases are thought to be from low- to middle-income countries. As per the same study, even if those countries implement HPV vaccine coverage for middle school-aged girls, the number of new cases of cervical cancer will only lower after three to four decades. ${ }^{16}$

In Oman, a previous study in a tertiary hospital reported that women had insufficient knowledge regarding cervical cancer, its risk factors and methods of screening. ${ }^{17}$ Therefore, the present study aimed, first, to assess the knowledge of cervical cancer as well as the knowledge of and attitude towards HPV and its vaccine among Omani women throughout Oman and, second, to establish a correlation between their knowledge/attitude and sociodemographic factors. Assessing women's knowledge and attitude regarding HPV infection and its consequences will help in assessing the acceptability of introducing a well-structured cervical cancer screening programme. Furthermore, assessing the participants' knowledge and acceptability of the available vaccine will aid the concerned decision-makers in determining whether to add the vaccine to the national immunisation schedule.

\section{Methods}

A multi-centric cross-sectional study was carried out in primary health centres across Oman from September 2019 to February 2020. Oman comprises 11 governorates and the number of health centres varies from one governorate to another. Each of these health centres serves the general population with the aim of having one health centre per 10,000 people. Health centres provide a single location for primary care teams to work from and deliver primary healthcare needs. These clinics are well developed in terms of the availability of trained and qualified family physicians, appointment systems and a wide range of investigations and medications. A total of 18 health centres were randomly selected from each governorate. This was done by categorising the governorates as either 'large' or 'small' based on population size. The enrolled health centres were arranged based on the population of the catchment area and the number of outpatient visits, details of which were obtained from the Oman Health Records 2019. Of the 11 governorates, seven were categorised as large and four as small. Two health centres were randomly selected from the larger governorates and one health centre from the less populated governorates using a simple random sampling method. The number of participants from each centre was then calculated based on the proportion of outpatient visits in that health centre compared to the total number of outpatient visits. The participants were selected randomly using a systematic random sampling method, which chose every second adult female visiting the health centre for any reason (medical or non-medical) during the study period. The target population was Omani women aged 18 years and older who were attending the health centre for any service. Women who could not read, those who did not speak Arabic or English, those with learning difficulties or dementia, acutely sick women who required immediate care or those in a hurry were excluded from the study.

Based on the anticipated level of knowledge regarding cervical cancer and screening for cervical cancer, the sample size was determined as $50 \%$, with a 5\% margin of error, 95\% confidence level and 5\% two-tailed alpha error. The calculated sample size was 768 . In addition, a $4 \%$ non-response rate to the survey was anticipated; therefore, a sample size of 800 was considered for the study. The calculation was done using the OpenEpi software (Emory University, Atlanta, Georgia, USA).

A structured questionnaire was used for data collection, which had been tested in a previous study in Oman. ${ }^{17}$ The average time taken to fill the questionnaire ranged between 10 and 15 minutes and this was done by face-to-face interview. The study was anonymous, and the participants were assigned a unique code, which was later used for data analysis.

The survey consisted of three main parts. The first part concerned the sociodemographic characteristics 
of the participants including their age, marital status, age at first marriage, number of marriages, total number of children, number of daughters, their level of education and that of their spouses', employment status, whether their degree was related to healthcare, total monthly income and if their income affected their regular gynaecological reviews. The second part assessed the participants' cervical cancer risk factors including history of smoking, exercise, use of oral contraceptive methods, history of abortion, history of sexually transmitted infection (STI), history of HPV infection and personal and family history of cervical cancer. Moreover, the participants were asked about their immunity status (i.e. whether they or their spouses had a history of HIV infection and whether they were using immunosuppressant medications). The third part assessed knowledge and awareness regarding cervical cancer and HPV. Questions included whether the participants had heard of cervical cancer, their source of information and whether they thought it was among the most common cancers leading to death worldwide. They were questioned about their knowledge of the warning signs of cervical cancer, for example, intermenstrual bleeding, persistent low back pain, persistent foul-smelling vaginal discharge, dyspareunia, menorrhagia, persistent diarrhoea, postmenopausal bleeding, persistent pelvic pain, postcoital bleeding, blood in urine or stool and unexplained weight loss. Furthermore, the knowledge of factors that affect the chances of developing cervical cancer, including a history of infection with HPV, smoking, weakened immunity of self or spouse, longterm use of contraceptive pills, early marriage before the age of 16 years, having many children $(\geq 3)$, family history of cervical cancer and, finally, failure to get screened for cervical cancer, were assessed. The last few questions in this part were regarding HPV and its vaccine-whether they had ever heard of this vaccine and whether they generally accepted the provision of the HPV vaccine to middle school-aged girls and, more specifically, to their own daughters. Finally, they were asked if their knowledge, awareness and practice regarding cervical cancer and its screening were influenced by the conservative nature of the Omani society.

To assess the participants' knowledge, all knowledge-related questions were compiled and a scoring system was created. Each correct answer was given one point and the total possible score was 22 . The scores were then divided into two categories: not knowledgeable (scores of <12) and knowledgeable (scores of 12-22).

Data analysis was performed using the Statistical Package for the Social Sciences (SPSS), Version 23
(IBM Corp, Chicago, Illinois, USA). Descriptive analyses were conducted for sample characteristics. Continuous variables were presented as means and standard deviations. Categorical variables were reported as frequencies and percentages. Pearson's chi-square $\left(x^{2}\right)$ test was used when appropriate to determine significance. Fisher's exact tests were used for low cell frequencies. A $P$ value of 0.05 or less was considered statistically significant. Missing data were not included in the analyses.

Ethical approval for the study was obtained from the Research and Ethics Committee of the Department of Planning and Studies, Ministry of Health, Oman (MOH/CSR/18/9478). Participation in the study was voluntary and written consent with a statement of confidentiality was obtained from all participants. The purpose and objectives of the research were explained to all participants. Privacy, confidentiality and the right to withdraw at any time were assured.

\section{Results}

A total of 805 women participated and completed the study (response rate: $89 \%$ ). Most of the participants were in the age group of $21-30$ years $(38.9 \%)$ and $31-40$ years $(40.6 \%)$ [Table 1$]$. More than half of the participants were undergraduates (55.7\%). Out of the remaining participants, most had secondary school diplomas (38.7\%). The participants were almost equally divided between those with employment (46.5\%) and those without (53.5\%). Approximately one-fifth of the participants had degrees related to healthcare (20.6\%). Only a fifth of the women surveyed were never married (17.0\%), while the majority were married, divorced or widowed (83.1\%). More than half were married between the ages of 18-25 years (55.9\%). Only a small number were married before completing 18 years of age (8.0\%). The number of children of each participant varied greatly from $1-13$, with an average of $2.52 \pm 2.44$. The number of daughters also varied, with an average of $1.25 \pm 1.49$, among which $42 \%$ did not have any, followed by a quarter who had one daughter (24.3\%). Almost half of the participants' husbands had secondary school diplomas (40.7\%) followed by undergraduate degrees (37.8\%) The participants' income also varied greatly: $20.2 \%$ reported having a low income of less than 500 Omani rial (OMR) per month, and $20.4 \%$ stated having an income of 1,0002,500 OMR a month. The majority of the participants (78.3\%) indicated that their financial status did not affect their visits to the gynaecologist.

Almost all of the participants were non-smokers (99.5\%). Around one-third did not exercise (31.9\%), while only $69(8.6 \%)$ exercised regularly around $4-5$ 
Table 1: Knowledge of cervical cancer among Omani women $(\mathrm{N}=805)$

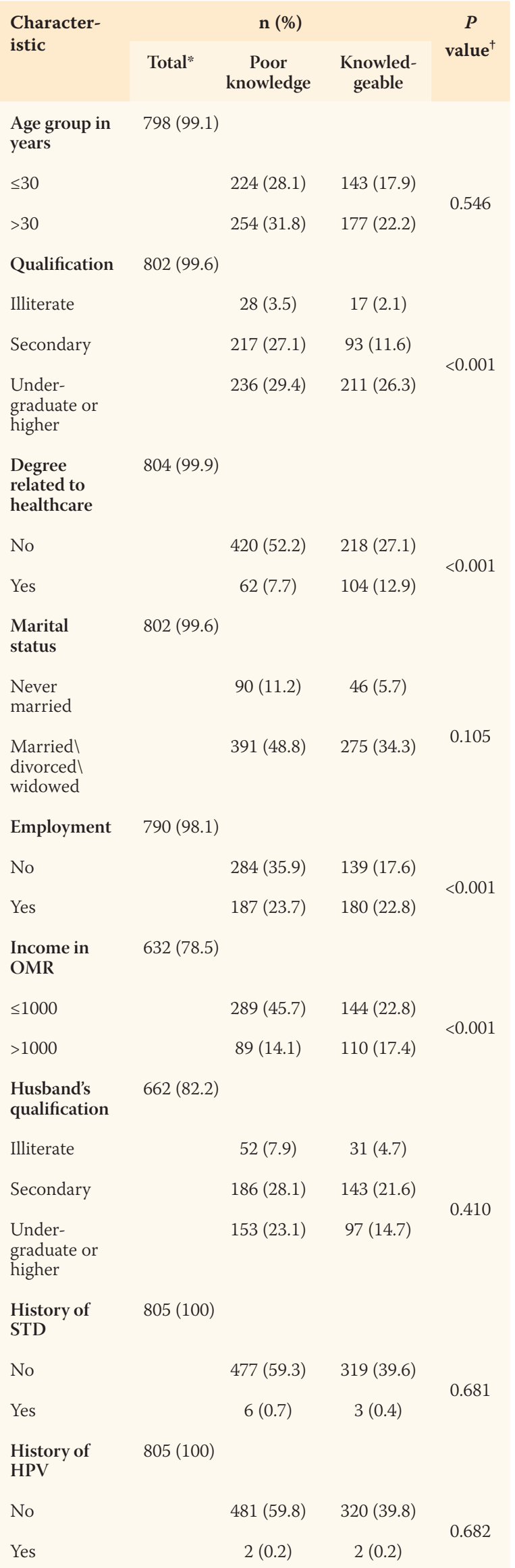

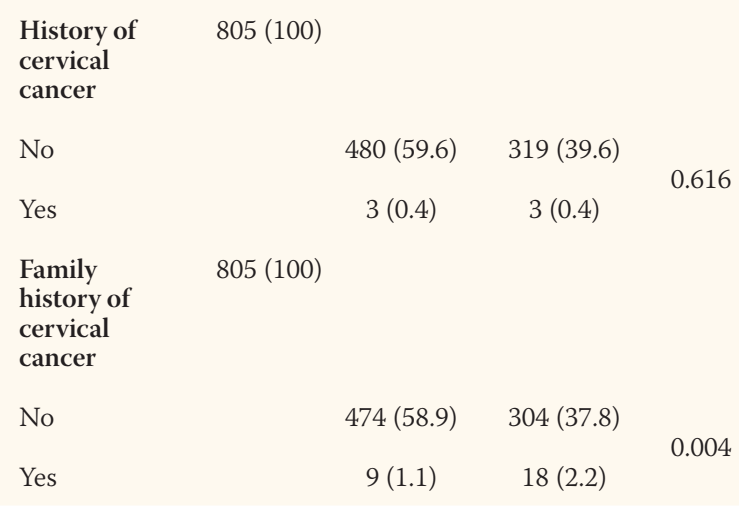

$O M R=$ Omani rial; $S T D=$ sexually transmitted disease; $H P V=$ human papillomavirus.

"Missing data were not included in the statistical analysis. ${ }^{\dagger} U$ sing Chisquare test.

times a week. Most of the women (78.9\%) were not using any contraceptive methods. Approximately onethird (30.1\%) had a history of abortion, with a small proportion having had more than two abortions $(6.6 \%)$. Few (1.1\%) had a history of STI and even less $(0.5 \%)$ had previously been infected with HPV. Of all the participants, only six $(0.7 \%)$ had a history of cervical cancer and 27 (3.4\%) had a family history of cervical cancer to their knowledge. Few (0.6\%) reported having low immunity and only one $(0.1 \%)$ reported having a husband with low immunity.

When questioned regarding their knowledge about cervical cancer, more than two-thirds of the participants $(67.5 \%)$ reported having heard of cervical cancer. Most of them had gained this knowledge from social media (33.0\%), followed by their healthcare provider (16.9\%), television programmes or advertisements (16.5\%), schools or universities (12.9\%), family and friends (8.2\%) and written media such as magazines and newspapers (8.1\%). The majority (60.2\%) did not know that cervical cancer is a leading cause of death and only a quarter (26.3\%) thought it was. The warning signs of cervical cancer most frequently identified by the participants included spotting between periods (47.3\%), vaginal discharge (41.9\%), persistent pelvic pain $(41.6 \%)$ and postmenopausal bleeding (39.0\%). In addition, just under half of the participants identified persistent low back pain (47.3\%), menorrhagia (38.9\%), postcoital bleeding (35.5\%), dyspareunia (34.7\%) and weight loss (31.1\%) as warning signs. However, blood in the stool and urine (26.2\%) and diarrhea (12.3\%) were seldom identified as warning signs.

When questioned regarding factors that increase the chances of developing cervical cancer, most of the participants agreed that the following are risk factors for cervical cancer: immunosuppression (56.9\%), having a family history of cervical cancer 
Table 2: Attitudes of Omani women towards administering the human papillomavirus vaccine to their daughters and/or middle school-aged girls

\begin{tabular}{|c|c|c|c|c|c|c|}
\hline \multirow{3}{*}{$\begin{array}{l}\text { Character- } \\
\text { istic }\end{array}$} & \multicolumn{6}{|c|}{ Acceptability of administering HPV vaccine, $\mathbf{n}(\%)^{*}$} \\
\hline & To & ters & $\underset{\text { value }^{+}}{P}$ & & $\begin{array}{l}\text { dle } \\
\text { ged }\end{array}$ & $\underset{\text { value }^{+}}{P}$ \\
\hline & No & Yes & & No & Yes & \\
\hline
\end{tabular}

Age group in years

$\leq 30$

$\begin{array}{cc}43 & 172 \\ (43.9) & (45.6)\end{array}$

$50 \quad 157$

$>30$

$\begin{array}{cc}55 & 206 \\ (56.1) & (54.5)\end{array}$

(43.9) (47.4)

0.760

$64 \quad 174$

(56.1) (52.6)

Total

$98 \quad 378$

$114 \quad 331$

Qualification

Illiterate

$\begin{array}{cc}10 & 18 \\ (10.0) & (4.8)\end{array}$

0.052

$12 \quad 15$

$(10.4) \quad(4.5)$

$\begin{array}{lcc}\text { Secondary } & 47 & 133 \\ & (47.0) & (35.3)\end{array}$

(47.0) (35.3)

$62 \quad 105$

(53.9) (31.6)

$41 \quad 212$

(35.7) (63.9)

$\begin{array}{lcc}\text { graduate } & (43.0) & \text { (59.9) }\end{array}$

or higher

$100 \quad 377$

Total

Degree related to healthcare

No

$(79.0) \quad(76.1)$

$98 \quad 249$

(85.2) (75.2)

0.036

Yes

$\begin{array}{cc}21 & 90 \\ (21.0) & (23.9)\end{array}$

$17 \quad 82$

(14.8) (24.8)

Total

$100 \quad 377$

Marital status

married

$19 \quad 62$

(19.2) (16.4)

0.809

22

(19.1)

$93 \quad 276$

Married/ $\quad 80 \quad 315$

divorced/ (80.8) (83.6)

(80.9) (84.1)

widowed

$99 \quad 377$

Total

$115 \quad 328$

Employment

No $53 \quad 189$

$\begin{array}{lll}\text { Yes } & 44 & 187\end{array}$

$\begin{array}{cc}44 & 187 \\ (45.4) & (49.7)\end{array}$

Total

$97 \quad 376$

$0.194 \quad 69 \quad 157$

(61.6) (47.7)

$43 \quad 172$

(38.4) (52.3)

$112 \quad 329$

Income in OMR

$\begin{array}{lcccccc}\leq 1000 & 56 & 197 & 0.333 & 60 & 172 & 0.270 \\ \text { OMR } & (70.0) & (65.7) & & (67.4) & (65.4) & \\ >1000 & 24 & 103 & & 29 & 91 & \\ \text { OMR } & (30.0) & (34.3) & & (32.6) & (34.6) & \\ \text { Total } & 80 & 300 & & 89 & 263 & \end{array}$

Husband's qualification

Illiterate

$\begin{array}{cc}15 & 33 \\ (18.8) & (10.5)\end{array}$

$18 \quad 28$

0.284

\begin{tabular}{|c|c|c|c|c|}
\hline Secondary & $\begin{array}{c}38 \\
(47.5)\end{array}$ & $\begin{array}{c}165 \\
(52.5)\end{array}$ & $\begin{array}{c}42 \\
(44.2)\end{array}$ & $\begin{array}{c}140 \\
(51.3)\end{array}$ \\
\hline $\begin{array}{l}\text { Under- } \\
\text { graduate } \\
\text { or higher }\end{array}$ & $\begin{array}{c}27 \\
(33.8)\end{array}$ & $\begin{array}{c}116 \\
(36.9)\end{array}$ & $\begin{array}{c}35 \\
(36.8)\end{array}$ & $\begin{array}{c}105 \\
(38.5)\end{array}$ \\
\hline Total & 80 & 314 & 95 & 21 \\
\hline
\end{tabular}

History of STD

\begin{tabular}{|c|c|c|c|c|c|}
\hline No & $\begin{array}{c}100 \\
(100.0)\end{array}$ & $\begin{array}{c}371 \\
(98.1)\end{array}$ & 0.155 & $\begin{array}{c}115 \\
(100.0)\end{array}$ & $\begin{array}{c}328 \\
(98.8)\end{array}$ \\
\hline Yes & $0(0.0)$ & 7 (1.9) & & $\begin{array}{c}0 \\
(0.0)\end{array}$ & $4(1.2)$ \\
\hline Total & 100 & 378 & & 115 & 332 \\
\hline
\end{tabular}

History of HPV

\begin{tabular}{|c|c|c|c|c|c|}
\hline No & $\begin{array}{c}100 \\
(100.0)\end{array}$ & $\begin{array}{c}376 \\
(99.5)\end{array}$ & 0.743 & $\begin{array}{c}115 \\
(100.0)\end{array}$ & $\begin{array}{c}330 \\
(99.4)\end{array}$ \\
\hline Yes & $0(0.0)$ & $2(0.5)$ & & $\begin{array}{c}0 \\
(0.0)\end{array}$ & $2(0.6)$ \\
\hline Total & 100 & 378 & & 115 & 332 \\
\hline
\end{tabular}

History of cervical cancer

$\begin{array}{lcccccc}\text { No } & 99 & 376 & 0.796 & 115 & 327 & 0.105 \\ & (99.0) & (99.5) & & (100.0) & (98.5) & \\ \text { Yes } & 1(1.0) & 2(0.5) & & 0 & 5(1.5) & \\ & & & & (0.0) & & \\ \text { Total } & 100 & 378 & & 115 & 332 & \end{array}$

Family history of cervical cancer

$\begin{array}{lcccccc}\text { No } & 99 & 364 & 0.377 & 114 & 317 & 0.160 \\ & (99.0) & (96.3) & & (99.1) & (95.5) & \\ \text { Yes } & 1(1.0) & 14 & & 1 & 15 & \\ & & (3.7) & & (0.9) & (4.5) & \\ \text { Total } & 100 & 378 & & 115 & 332 & \end{array}$

Do you have daughters?

\begin{tabular}{|c|c|c|c|c|c|}
\hline No & $\begin{array}{c}37 \\
(37.0)\end{array}$ & $\begin{array}{c}170 \\
(45.0)\end{array}$ & 0.234 & $\begin{array}{c}44 \\
(38.3)\end{array}$ & $\begin{array}{c}148 \\
(44.6)\end{array}$ \\
\hline Yes & $\begin{array}{c}63 \\
(63.0)\end{array}$ & $\begin{array}{c}208 \\
(55.0)\end{array}$ & & $\begin{array}{c}71 \\
(61.7)\end{array}$ & $\begin{array}{c}184 \\
(55.4)\end{array}$ \\
\hline Total & 100 & 378 & & 115 & 332 \\
\hline
\end{tabular}

"I don't know"/"not sure responses" were not included in the statistical analysis. ${ }^{\dagger}$ Using chi-square test.

(53.3\%), never being screened for cervical cancer before (49.7\%), smoking (48.1\%), long-term use of oral contraceptive pills (36.6\%) and having a husband with a weakened immune system (34.4\%). On the other hand, very few respondents thought that early marriage (17.0\%) and having many children (9.3\%) played a role in developing cervical cancer. Almost half of the respondents (49.7\%) did not know whether HPV infection was a risk factor and some (11.4\%) thought it was not a risk factor.

Regarding the knowledge score, 483 (60.0\%) participants were categorised as having poor 
knowledge, with a score of $<12$, while $322(40.0 \%)$ were deemed knowledgeable, with a score of $\geq 12$. The knowledge score was significantly associated with the participants' qualifications $(P<0.001)$ and whether their degree was related to healthcare $(P<0.001)$. Most women who were categorised as knowledgeable were undergraduates or had a higher degree (65.7\%). Considering the relationship between the participants' field of study, particularly whether it was related to healthcare and their knowledge score, more than half of the participants had poor knowledge (59.9\%), with a few being in healthcare-related fields (7.7\%). The knowledge score was also significantly associated with employment status $(P<0.001)$, income $(P<0.001)$ and a family history of cervical cancer $(P=0.004)$. The knowledge score was not significantly associated with the other sociodemographic characteristics or with a previous history of STI, HPV infection or cervical cancer [Table 1].

Two-thirds of the participants (67.0\%) had never heard of HPV. Even though only 81 women (10.1\%) had heard of the HPV vaccine, 332 (41.2\%) were accepting of offering the vaccine to middle schoolaged girls and almost half (47.0\%) of the participants agreed that vaccinating their daughters was a good decision. Furthermore, $48.3 \%$ of the participants admitted that the conservative nature of Omani society affected their knowledge of cervical cancer. There was no association between any of the factors and the participants' acceptance of the provision of the HPV vaccine to their own daughters. However, there was a significant association between the participants' acceptance of vaccinating school children and their level of education $(P<0.001)$, whether their field of study was related to healthcare $(P=0.036)$ and their employment status $(P=0.014)$. On the contrary, there was no association between the participants' agreement towards vaccination and whether they had daughters [Table 2].

\section{Discussion}

Even though cervical cancer is the third most common cancer among Omani women aged 15-44 years, there is no well-structured national screening programme. ${ }^{5}$ The unavailability of cervical cancer screening and Pap smear testing at the primary healthcare level has led to a lack of knowledge regarding cervical cancer. In the current study, $67.5 \%$ of the participants had heard of cervical cancer, which is low compared to a previous similar study in Oman where more than $80 \%$ of the participants had heard of cervical cancer. ${ }^{17}$ The main source of information for the participants in the present study was social media (33.0\%), followed by healthcare providers (16.9\%). This observation is consistent with the findings of studies from other Arabic countries such as Qatar, Hispanic communities in the US and some Asian countries including India. ${ }^{18-20}$ However, these findings are contrary to those of a study conducted in Italy among young adult women, which found healthcare providers to be the primary and most trusted source of information. ${ }^{21}$ This suggests the possibility that national education and awareness programmes are deficient in Oman or are not within the reach of the public. Social media has become an important platform that can be utilised in educating the public about cervical cancer and the HPV vaccine, especially considering that it is currently one of the fastest and easiest means of delivering information. Hence, it could be wisely used by healthcare providers, provided the information is well-prepared and structured.

A previous study from Oman found that the majority of undergraduates had inadequate knowledge regarding cervical cancer which was found to be $100 \%, 59.5 \%$ and $92.4 \%$ for patients, staff and current students, respectively. ${ }^{17}$ Similarly, the present study found that participants demonstrated poor knowledge despite their educational level or employment status, which is indicative of the fact that the public's overall exposure to cervical cancer awareness, whether through advertisement, their healthcare providers or their schools, is lacking. This highlights the need to utilise different resources to increase awareness of cervical cancer and to focus more on the role of healthcare professionals in delivering the required information, as, being the most reliable of sources, they are uniquely qualified to respond to any enquiry and offer appropriate guidance to the public.

In terms of knowledge regarding cervical cancer, the results of the present study were consistent with those of studies done in Qatar and Kuwait. ${ }^{18,22}$ People who had better knowledge were mostly those who were undergraduates or those aged 31 years or older. On the other hand, women under 30 years of age, recently married women and uneducated women were found to possess inadequate knowledge. Although most of the respondents in the present study were educated, only $40.0 \%$ were considered knowledgeable. Contrary to the findings of previous studies, even highly educated participants were found to be unaware of cervical cancer in the present study. This could be because the population size in a previous study done in Oman was smaller and most of the participants were hospital staff and nursing students who would have previously been exposed to information regarding, if not had patients with, cervical cancer and/or HPV. ${ }^{17}$ 
Regarding knowledge of HPV and its vaccine, among the participants of the present study, only $15.8 \%$ had heard of HPV compared to $34.5 \%$ in a study conducted in Saudi Arabia. In the same study, 29.9\% of participating Saudi women were aware of the HPV vaccine compared to only $10.1 \%$ in the present study. ${ }^{23}$ Both these figures are very low when compared to the $79.1 \%$ of participants who knew of the HPV vaccine in a study done in the UK, USA, and Australia. ${ }^{24}$ This calls for a nationwide awareness programme to educate the Omani public regarding HPV and its implications.

Despite the poor knowledge regarding HPV and its vaccine, the population of the present study was found to be accepting of vaccinating middle schoolaged girls, including their own daughters. This could indicate the public's trust in the health authorities of the country. The acceptability rate of participants towards vaccinating their daughters was $47.1 \%$, which is considered low when compared to $83.7 \%$ in Thailand, $81.8 \%$ in Bahrain and 64.3\% in Saudi Arabia. ${ }^{23,25-27}$ Though the acceptance shown towards the HPV vaccine is comparably low, initiatives must be taken to increase acceptability of the vaccine and to make it available for eligible candidates.

The strength of the current study lies in the diversity of the respondents. It is the first national study from Oman to assess the knowledge and awareness of and attitude towards cervical cancer and HPV. The results of this study can, therefore, be generalised to the entire population. Moreover, the response rate was high, likely due to the chosen data collection method (face-to-face interviews), which may have helped to build a stronger rapport with the respondents, allowing for more accurate and complete responses. The limitations of this study include the length of the questionnaire and the fact that the interviews were conducted in the waiting areas of primary healthcare facilities, which can often be crowded. Finally, the inclusion of questions referring to the participants' past experiences and the face-to-face interview setup itself could have inadvertently led to recall or response bias.

\section{Conclusion}

Most participants had poor knowledge of cervical cancer and HPV. Even those with a personal or family history of cervical cancer were not aware of HPV and its role. Regardless of this, most participants were open and accepting of the idea of offering the HPV vaccine to middle school-aged girls and even their daughters. Community outreach programmes may help in enriching public knowledge and, possibly, correct misinformation and myths regarding cervical cancer and HPV.

\section{AUTHORS' CONTRIBUTIONS}

MR, TY and RK conceived the presented research idea and conducted the literature review. MR and TY, under the supervision of RK, designed the research methodology. MR and TY were involved in the data collection and date entry. MR, TY and RK analysed and interpreted the results. MR was a major contributor in writing the manuscript in consultation with TY and RK. RK was the research supervisor who guided MR and TY throughout the project. All authors approved the final version of the manuscript.

\section{ACKNOWLEDGEMENT}

We would like to thank Dr Gauhar Rizvi of Sultan Qaboos University, Muscat, Oman, and Mr Sachin Jose of Oman Medical Specialty Board, Muscat, Oman, for their invaluable help with the statistics. We would also like to extend our thanks to our research assistants who made it possible to conduct this research project at the national level.

\section{CONFLICT OF INTEREST}

The authors declare no conflicts of interest.

\section{FUNDING}

This research has received funding from Sultan Qaboos University Hospital (Grant \#RF/MED/ FAMCO/19/04)

\section{References}

1. Jhingran A, Russel AH, Seiden MV, Duska LR, Goodman A, Lee SL, et al. Cancers of the cervix, vulva, and vagina. In: Niederhuber JE, Armitage JO, Doroshow JH, Kastan MB, Tepper JE, Eds. Clinical Oncology, 6th ed. Amsterdam, The Netherlands: Elsevier, 2019. pp. 1468-507.

2. Green J, Berrington de Gonzalez A, Sweetland S, Beral V, Chilvers C, Crossley B, et al. Risk factors for adenocarcinoma and squamous cell carcinoma of the cervix in women aged 20-44 years: The UK National Case-Control Study of Cervical Cancer. Br J Cancer 2003; 89:2078-86. https://doi.org/10.1038/ sj.bjc. 6601296

3. Al-LawatiZ,KhamisFA,Al-HamdaniA,Al-KalbaniM, RamadhanFA, Al-Rawahi TR, et al. Prevalence of human papilloma virus in Oman: Genotypes 82 and 68 are dominating. Int J Infect Dis 2020; 93:22-7. https://doi.org/10.1016/j.ijid.2019.12.038.

4. World Health Organization. The Global Health Observatory: GLOBACAN 2020 Cervix Uteri. From: https://gco.iarc.fr/ today/data/factsheets/cancers/23-Cervix-uteri-fact-sheet.pdf Accessed: Sep 2021.

5. World Health Organization. The Global Health Observatory: GLOBACAN 2020 Oman. From: https://gco.iarc.fr/today/data/ factsheets/populations/512-oman-fact-sheets.pdf Accessed: Sep 2021. 
6. Bruni L, Albero G, Serrano B, Mena M, Gómez D, Muñoz J, et al. ICO/IARC Information Centre on HPV and Cancer (HPV Information Centre). Human papillomavirus and related diseases in Oman. Summary report 17 June 2019. From: https:// hpvcentre.net/statistics/reports/OMN.pdf Accessed: Sep 2021.

7. Güdücü N, Gönenç G, İşçi H, Yiğiter AB, Dünder İ. Awareness of human papilloma virus, cervical cancer and HPV vaccine in healthcare workers and students of medical and nursing schools. J Clin Exp Invest 2012; 3:318-25. https://doi.org/10.57 99/ahinjs.01.2012.03.0171.

8. Arbyn M, Weiderpass E, Bruni L, de Sanjosé S, Saraiya M, Ferlay J, et al. Estimates of incidence and mortality of cervical cancer in 2018: A worldwide analysis. Lancet Glob Health 2020; 8:e191-203. https://doi.org/10.1016/S2214-109X(19)30482-6.

9. Gamaoun R. Knowledge, awareness and acceptability of antiHPV vaccine in the Arab states of the Middle East and North Africa region: A systematic review. East Mediterr Health J 2018; 24:538-48. https://doi.org/10.26719/2018.24.6.538.

10. Ministry of Health, Oman. Manual on expanded program on immunisation. From: www.moh.gov.om/documents/27292 8/4017900/EPI_Manual.pdf/7cdf4393-3ff9-3575-f911c460ada5831b Accessed: Sep 2021.

11. Cancer Research UK. Cervical cancer statistics. From: https:// www.cancerresearchuk.org/health-professional/cancerstatistics/statistics-by-cancer-type/cervical-cancer Accessed: Oct 2019.

12. Peto J, Gilham C, Fletcher O, Matthews FE. The cervical cancer epidemic that screening has prevented in the UK. Lancet 2004; 364:249-56. https://doi.org/10.1016/S0140-6736(04)16674-9.

13. Siegel R, Naishadham D, Jemal A. Cancer statistics, 2012. CA Cancer J Clin 2012; 62:10-29. https://doi.org/10.3322/caac.20138.

14. Bray F, Ferlay J, Soerjomataram I, Siegel RL, Torre LA, Jemal A. Global cancer statistics 2018: GLOBOCAN estimates of incidence and mortality worldwide for 36 cancers in 185 countries. CA Cancer J Clin 2018; 68:394-424. https://doi.org/10.3322/ caac. 21492 .

15. Lei J, Ploner A, Elfström KM, Wang J, Roth A, Fang F, et al. HPV vaccination and the risk of invasive cervical cancer. N Engl J Med 2020; 383:1340-8. https://doi.org/10.1056/NEJMoa1917338.

16. Simms KT, Steinberg J, Caruana M, Smith MA, Lew JB, Soerjomataram I, et al. Impact of scaled up human papillomavirus vaccination and cervical screening and the potential for global elimination of cervical cancer in 181 countries, 2020-99: A modelling study. Lancet Oncol 2019; 20:394-407. https://doi. org/10.1016/S1470-2045(18)30836-2.
17. Nasar A, Waad A, Atheer A, Nasra A. Awareness of cervical cancer and Pap smear testing among Omani women. Asian Pac J Cancer Prev 2016; 17:4825-30. https://doi.org/10.22034/ APJCP.2016.17.11.4825

18. Al-Meer FM, Aseel MT, Al-Khalaf J, Al-Kuwari MG, Ismail MFS. Knowledge, attitude and practices regarding cervical cancer and screening among women visiting primary health care in Qatar. East Mediterr Health J 2011; 17:855-61. https://doi.org/10.267 19/2011.17.11.856

19. Ramirez AG, Suarez L, Laufman L, Barroso C, Chalela P. Hispanic women's breast and cervical cancer knowledge, attitudes, and screening behaviors. Am J Health Promot 2000; 14:292-300. https://doi.org/10.4278/0890-1171-14.5.292.

20. Roy B, Tang TS. Cervical cancer screening in Kolkata, India: Beliefs and predictors of cervical cancer screening among women attending a women's health clinic in Kolkata, India. J Cancer Educ 2008; 23:253-9. https://doi.org/10.1080/08858190802189105.

21. Donati S, Giambi C, Declich S, Salmaso S, Filia A, Ciofi degli Atti ML, et al. Knowledge, attitude and practice in primary and secondary cervical cancer prevention among young adult Italian women. Vaccine 2012; 30:2075-82. https://doi.org/10.1016/j.vaccine.20 12.01 .057

22. Al Sairafi M, Mohamed FA. Knowledge, attitudes, and practice related to cervical cancer screening among Kuwaiti women. Med Princ Pract 2009; 18:35-42. https://doi.org/10.1159/000163044.

23. Hussain AN, Alkhenizan A, McWalter P, Qazi N, Alshmassi A, Farooqi S, et al. Attitudes and perceptions towards HPV vaccination among young women in Saudi Arabia. J Family Community Med 2016; 23:145-50. https://doi.org/10.4103/2230-8229.189107.

24. Marlow LA, Zimet GD, McCaffery KJ, Ostini R, Waller J. Knowledge of human papillomavirus (HPV) and HPV vaccination: An international comparison. Vaccine 2013; 31:763-9. https:// doi.org/10.1016/j.vaccine.2012.11.083

25. Ling WY, Razali SM, Ren CK, Omar SZ. Does the success of a school-based HPV vaccine programme depend on teachers' knowledge and religion? -- A survey in a multicultural society. Asian Pac J Cancer Prev 2012; 13:4651-4. https://doi.org/10.73 14/apjcp.2012.13.9.4651.

26. Moosa K, Alsayyad AS, Quint W, Gopala K, DeAntonio R. An epidemiological study assessing the prevalence of human papillomavirus types in women in the Kingdom of Bahrain. BMC Cancer 2014; 14:905. https://doi.org/10.1186/1471-240714-905.

27. Jassim G, Obeid A, Al Nasheet HA. Knowledge, attitudes, and practices regarding cervical cancer and screening among women visiting primary health care centres in Bahrain. BMC Public Health 2018; 18:128. https://doi.org/10.1186/s12889-018-5023-7. 